
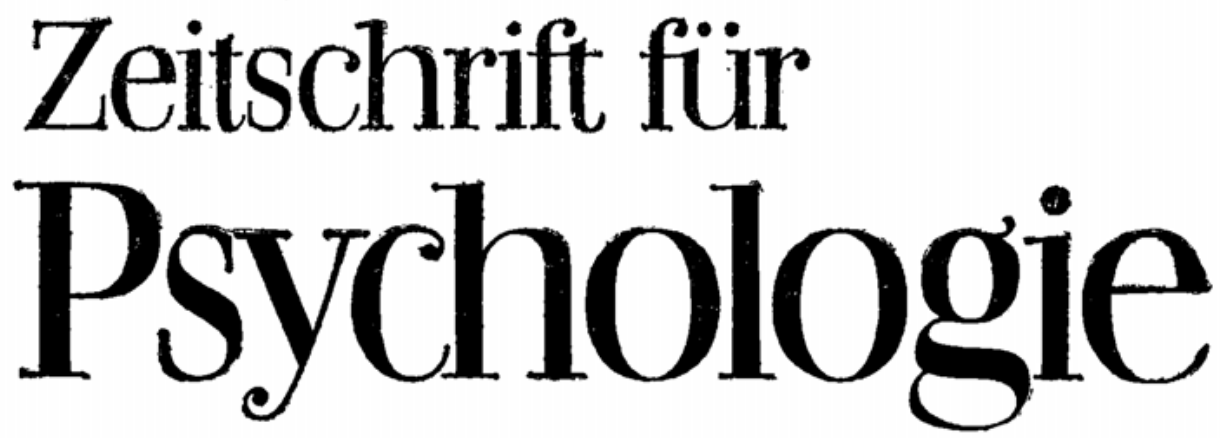

\title{
mitZeitschrift für angewandte Psychologie
}

Schriftleitung

WERNER FISCHEL, Leipzig

und

FRIEDHART KLIX, Berlin

Redaktion

JÜRGEN MEHL, Berlin

Unter Mitarbeit von

B. G. ANANJEW, Leningrad; H. DƯKER, Marburg; H.-J. EYSENCK, London; P. FRAISSE, Paris; J. J. GIBSON, Ithaca, N. Y.; H. HIEBSCH, Jena; A. KOSSAKOWSKI, Berlin; D. KOVÁC, Bratislava; A. N. LEONTJEW, Moskau; B. F. LOMOW, Leningrad; L. A. LURIJA, Moskau; D. A. OSCHANIN, Moskau; J. PIAGET, Genf; G. ROSENFELD, Berlin; K. SATO, Kyoto; W. STRAUB, Dresden

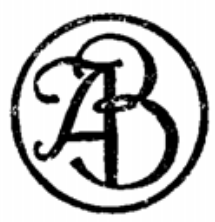

JOHANN AMBROSIUS BARTH LEIPZIG 